\title{
Efeito de aditivos na composição bromatológica e qualidade de silagens de coproduto do desfibramento do sisal
}

\section{Additives effect on chemical composition and quality of sisal co-product silage}

\author{
Luiz Gustavo Neves Brandão ${ }^{1}$; Luiz Gustavo Ribeiro Pereira ${ }^{2 *}$; \\ José Augusto Gomes de Azevêdo ${ }^{3}$; Rafael Dantas dos Santos ${ }^{4}$; \\ Gherman Garcia Leal de Araújo ; João Ricardo Rebouças Dórea ${ }^{6}$; \\ André Luis Alves Neves ${ }^{7}$
}

\section{Resumo}

Foram avaliadas as características fermentativas e o valor nutricional de silagem de coproduto do desfibramento do sisal (CDS) in natura ou aditivada. Os aditivos testados foram: farelo de soja, uréia, farelo de trigo, torta de dendê, pó da batedeira, torta de licuri e torta de algodão. Foram utilizados silos experimentais com capacidade de aproximadamente $15 \mathrm{~kg}$ de silagem. Avaliaram-se a composição bromatológica, os nutrientes digestíveis totais e o perfil fermentativo, 60 dias após a ensilagem. O delineamento experimental adotado foi o inteiramente casualizado com três repetições. O CDS in natura apresentou baixo teor de matéria seca (MS), 12,3\%, e os aditivos propiciaram aumentos nos teores de MS, com exceção da uréia. A silagem do CDS aditivada com farelo de soja $(\mathrm{pH}=4,9)$ e torta de dendê (ácido butírico $=0,07 \%$ na MS), diferiram, respectivamente, para valores de $\mathrm{pH}$ e ácido butírico, em relação à silagem com CDS in natura. A adição de farelo de soja, uréia, torta de algodão, farelo de trigo e torta de dendê causaram aumento do teor de proteína bruta (PB) em relação à silagem do CDS in natura. Houve aumento nos teores de FDN das silagens do CDS aditivados com torta de algodão ou dendê (60,1 e 66,2\% de FDN na MS) comparados à silagem CDS in natura (42,9\% na MS). As silagens de CDS in natura ou aditivadas foram consideradas como excelentes ou de boa qualidade.

Palavras-chave: Agave sisalana, nutrição, ruminantes, volumoso

\begin{abstract}
Fermentation profile and nutritional value of sisal co-product silage (SC) subjected to seven treatments (additives), were evaluated. The SC was ensiled in natura and added with: soy meal, urea, wheat meal,
\end{abstract}

\footnotetext{
${ }^{1}$ Prof. Assistente do Dept ${ }^{\circ}$. de Educação, Universidade do Estado da Bahia, UNEB, Senhor do Bonfim, BA. Bolsista de Produtividade em Pesquisa do CNPq. E-mail: gustasbaiano@hotmail.com

${ }^{2}$ Pesquisador da Embrapa Gado de Leite, Nutrição Animal, Juiz de Fora, MG. Bolsista de Produtividade em Pesquisa do CNPq. E-mail: luiz.gustavo@embrapa.br

${ }^{3}$ Prof. Adjunto do Dept ${ }^{\circ}$ de Ciências Agrárias e Ambientais, Universidade Estadual de Santa Cruz, UESC, Ilhéus, BA. Bolsista de Produtividade em Pesquisa do CNPq. E-mail: augustog@uesc.br

${ }^{4}$ Pesquisador da Embrapa Semiárido, Nutrição Animal, Petrolina, PE. E-mail:rafael.dantas@embrapa.br

${ }^{5}$ Pesquisador da Embrapa Semiárido, Nutrição Animal, Petrolina, PE. Bolsista de Produtividade em Pesquisa do CNPq. E-mail: gherman.araujo@embrapa.br

${ }^{6}$ Discente do Curso de Doutorado em Ciência Animal e Pastagens, Escola Superior de Agricultura "Luiz de Queiroz", ESALQ/ USP, Piracicaba, SP. E-mail: joaodorea@hotmail.com

${ }^{7}$ Gestor do Núcleo Nordeste da Embrapa Gado de Leite, Aracaju, SE. E-mail: andre.neves@embrapa.br

* Autor para correspondência
} 
palm kernel cake, $A$. sisalana dust, licuri cake and cottonseed cake. Experimental silos with capacity for approximately $15 \mathrm{~kg}$ of silage, were used. The silos were opened 60 days after ensilage process. It was used a completely randomized design with three replications. The SC in natura present low values of dry mater (DM) $12.3 \%$ and the additives increased dry matter silages, exception for urea. The SC silage additivated with soybean meal ( $\mathrm{pH} 4.9)$ and palm kernel cake (butyric acid $=0.07 \%$ $\mathrm{DM})$ differed, respectively, for $\mathrm{pH}$ and butyric acid, compared with in natura SC silage $(\mathrm{pH}=4.1$ and butyric acid $=0.03 \% \mathrm{DM}$ ). The addition of soybean meal, urea, cottonseed meal, wheat bran and palm kernel, increased crude protein (CP) of in natura SC silage. The NDF in silage increased with addition of cottonseed meal or palm kernel cake $(60.1$ and $66.2 \% \mathrm{DM})$ in relation in natura SC silage $(42.9 \% \mathrm{DM})$. The in natura and additivated silages of SC were considered as good or excellent quality.

Key words: Agave sisalana, nutrition, roughage, ruminants

\section{Introdução}

A região semiárida nordestina é a principal região produtora de sisal (Agave sisalana, Perrine) do Brasil (CONAB, 2008), devido principalmente às características edafoclimáticas que favorecem a produção desta agavácea. A "mucilagem", principal coproduto gerado após a obtenção da fibra das folhas do sisal, é utilizada na nutrição animal como alimento volumoso (GEBREMARIAM; MACHIN, 2008), porém, as informações científicas sobre seu valor nutricional e possíveis formas de armazenamento são escassos.

Nas regiões produtoras de sisal, alguns alimentos regionais de baixo custo podem ser uma alternativa como aditivo para a melhoria da qualidade das silagens do coproduto do sisal. Dentre eles destacam-se as tortas de licuri e de dendê, comumente encontrados na região, além do "pó da batedeira" (material oriundo da varredura dos galpões de armazenamento e processamento da fibra). A comparação destes com alimentos considerados referência (farelo de trigo e de soja), utilizados na forma de aditivos para silagem é importante.

Assim, foi realizado este trabalho com o objetivo de avaliar os efeitos dos aditivos na silagem do coproduto do desfibramento do sisal (CDS).

\section{Material e Métodos}

O ensaio foi conduzido na Embrapa Semiárido em Petrolina-PE e o coproduto do desfibramento do sisal (CDS) foi obtido de propriedades localizadas na região de ValenteBA, após o processamento das folhas de sisal em máquina denominada "Paraibana", de fabricação artesanal. O coproduto do desfibramento do sisal foi processado em peneira rotativa manual (SILVA et al., 1998), para retirada do excesso de fibras. Analisou-se a composição bromatológica dos diferentes aditivos (Tabela 1), bem como a composição bromatológica e o perfil fermentativos das silagens do coproduto do desfibramento do sisal (CDS) sob a adição de diferentes aditivos, compondo os seguintes tratamentos: CDS in natura; CDS $+10 \%$ de farelo de soja; CDS $+0,5 \%$ de uréia; CDS $+10 \%$ de farelo de algodão; CDS $+10 \%$ de farelo de trigo; CDS $+10 \%$ de torta de dendê; CDS $+10 \%$ de pó de batedeira e CDS $+10 \%$ de torta de licuri. Todas as proporções foram calculadas com base na matéria natural. 
Tabela 1. Composição dos aditivos utilizados nas silagens de coproduto do sisal.

\begin{tabular}{lcccccc}
\hline Item & $\begin{array}{c}\text { Farelo de } \\
\text { soja }\end{array}$ & $\begin{array}{c}\text { Farelo } \\
\text { de trigo }\end{array}$ & $\begin{array}{c}\text { Torta de } \\
\text { dendê }\end{array}$ & $\begin{array}{c}\text { Pó da } \\
\text { batedeira }\end{array}$ & $\begin{array}{c}\text { Torta de } \\
\text { licuri }\end{array}$ & $\begin{array}{c}\text { Torta de } \\
\text { algodão }\end{array}$ \\
\hline Matéria Seca (\%) & 91,9 & 90,5 & 91,1 & 87,1 & 86,1 & 92,7 \\
Proteína Bruta (\% MS) & 47,4 & 17,1 & 12,5 & 5,9 & 6,4 & 40,4 \\
Fibra em detergente neutro (\%MS) & 16,8 & 47,9 & 74,3 & 28,9 & 52,9 & 67,3 \\
Fibra em detergente ácido (\%MS) & 14,2 & 16,2 & 48,7 & 20,2 & 38 & 33,9 \\
Extrato Etéreo (\% MS) & 2,0 & 2,3 & 8,5 & 0,1 & 7,7 & 7,6 \\
\hline
\end{tabular}

Fonte: Elaboração dos autores.

Para a obtenção das silagens foram utilizados baldes de polietileno com capacidade para aproximadamente $15 \mathrm{~kg}$. Os silos foram pesados após o fechamento e antes da abertura (60 dias após a ensilagem). Determinou-se a recuperação de matéria seca como descrito por Zanine et al. (2010) e calculado pela fórmula: $\mathrm{RMS}=(\mathrm{MFab} x$ MSab)/(MFfe x MSfe) x 100, em que: RMS: taxa de recuperação de matéria seca (\%); MFfe: massa de forragem no fechamento $(\mathrm{kg})$; MSfe: teor de matéria seca da forragem no fechamento (\%); MFab: massa de forragem na abertura $(\mathrm{kg})$; MSab: teor de matéria seca da forragem na abertura (\%).

As amostras das silagens após abertura dos silos foram pré-secas em estufa de ventilação forçada a $60^{\circ} \mathrm{C}$ por $72 \mathrm{~h}$, e processadas em moinhos com peneiras dotadas de crivos de $1 \mathrm{~mm}$. Os parâmetros avaliados foram: matéria seca (MS), proteína bruta (PB), fibra em detergente neutro (FDN), fibra em detergente ácido (FDA), lignina (LIG), extrato etéreo (EE), proteína insolúvel em detergente neutro (PIDN), proteína insolúvel em detergente ácido (PIDA) e cinzas, segundo metodologias descritas por Silva e Queiroz (2002). Os teores de carboidratos totais (CHOT), carboidratos não fibrosos (CNF) foram obtidos pelas equações: $\mathrm{CHOT}=100-$ $(\mathrm{PB} \%+\mathrm{EE} \%+\mathrm{MM} \%)$ e $\mathrm{CNF}=100-(\mathrm{PB} \%+$ $\mathrm{EE} \%+\mathrm{MM} \%+\mathrm{FDN} \%$ ) de acordo com Sniffen et al. (1992). Os nutrientes digestíveis totais (NDT) foram estimados a partir da equação: NDT $=$ PBD + 2,25 x EED + FDNcpD + CNFD, (NRC, 2001) em que PBD, EED, FDNcp e CNFD significam, respectivamente, proteína bruta digestível, extrato etéreo digestível, fibra em detergente neutro (isenta de cinzas e proteína) digestível e carboidratos nãofibrosos digestíveis.

Com auxílio de prensa manual, foi obtido o suco da silagem, que foi utilizado para a determinação de $\mathrm{pH}$ (RIBEIRO et al., 2007) e nitrogênio amoniacal como parte do nitrogênio total $\left(\mathrm{N}-\mathrm{NH}_{3} /\right.$ NT), conforme Bolsen et al. (1992). Para análise dos ácidos orgânicos (lático, acético e butírico) em cromatografia líquida de alta resolução (HPLC), 10 $\mathrm{mL}$ do suco foram diluídos em água, acidificados com ácido sulfúrico $50 \%$ e filtrados em papel de filtro tipo Whatman ${ }^{\circledR} 54$ (ZANINE et al., 2010). Os parâmetros de qualificação das silagens adotados no presente trabalho foram os sugeridos por Tomich et al. (2003).

Adotou-se delineamento inteiramente casualizado com três repetições (CDS obtido de três diferentes propriedades), representadas pelo CDS e respectivos tratamentos obtidos em três propriedades rurais. O teste de Dunnett foi aplicado quando houve significância para as variáveis analisadas, comparado as silagens do CDS aditivadas em relação á silagem do CDS in natura. Os procedimentos estatísticos foram conduzidos com auxílio do software SAS (STATISTICAL ANALYSIS SYSTEM, 1999), adotando-se 0,05 como nível crítico de probabilidade para o erro tipo I.

\section{Resultados e Discussão}

A adição de aditivos nas silagens do coproduto do desfibramento do sisal (CDS) proporcionou 
aumento $(\mathrm{P}<0,05)$ na concentração de MS em relação a silagem do CDS in natura (12,3\% de MS), com exceção para a silagem do CDS aditivada com uréia, já que este aditivo teve menor representatividade em relação à massa ensilada (Tabela 2). Os baixos teores de MS são características das Agaváceas.

Aditivos absorventes de umidade são utilizados para elevar o teor de MS das silagens e aumentarem o valor nutritivo. Apesar da efetividade no incremento dos teores de MS, os valores encontrados, foram inferiores aos 20\%, limite recomendado por McDonald, Henderson e Heron (1991) como suficientes para produzir silagem de boa qualidade, quando não existe limitação de carboidratos solúveis. Assim, o baixo teor de MS pode ser fator limitante no armazenamento do coproduto do desfibramento do sisal na forma de silagem e, a présecagem ou a inclusão de maiores níveis de aditivos em relação aos utilizados no presente ensaio podem ser um recurso para aumentar a concentração de MS das silagens destes coprodutos.

Tabela 2. Teores de matéria seca (MS), nitrogênio amoniacal como parte do nitrogênio total (N-NH3), pH e recuperação de matéria seca (RMS) da silagem do coproduto do desfibramento do sisal (CDS) in natura e em função de diferentes aditivos.

\begin{tabular}{lccccccc}
\hline Tratamentos & $\begin{array}{c}\mathrm{MS} \\
(\%)\end{array}$ & $\begin{array}{c}\mathrm{N}^{\mathrm{NH}} / \mathrm{NT} \\
(\% \mathrm{MS})\end{array}$ & $\mathrm{pH}$ & $\begin{array}{c}\mathrm{RMS} \\
(\%)\end{array}$ & $\begin{array}{c}\text { Ac. } \\
\text { lático } \\
(\% \mathrm{MS})\end{array}$ & $\begin{array}{c}\text { Ac. } \\
\text { acético } \\
(\% \mathrm{MS})\end{array}$ & $\begin{array}{c}\text { Ac. } \\
\text { butírico } \\
(\% \mathrm{MS})\end{array}$ \\
\hline CDS in natura & 12,3 & 5,1 & 4,1 & 85,6 & 3,5 & 2,2 & 0,03 \\
& & & & & & & \\
CDS + Farelo de soja & 17,0 & 6,5 & $4,9 *$ & 84,5 & 6,6 & 2,4 & 0,04 \\
CDS + uréia & 11,8 & 7,9 & 4,5 & 85,0 & 6,5 & 2,8 & 0,05 \\
CDS + Torta de algodão & 18,1 & 6,6 & 4,7 & 81,7 & 5,5 & 2,9 & 0,05 \\
CDS + Farelo de trigo & $17,3^{*}$ & 5,6 & 4,4 & 87,5 & 3,0 & 2,6 & 0,06 \\
CDS + Torta de dendê & $19,0^{*}$ & 5,0 & 4,6 & 89,7 & 3,7 & 2,8 & $0,07 *$ \\
CDS + Pó da batedeira & $17,1^{*}$ & 3,8 & 4,2 & 90,9 & 2,6 & 2,5 & 0,05 \\
CDS + Torta de licuri & $19,4^{*}$ & 3,1 & 3,7 & 91,6 & 3,2 & 3,3 & 0,06 \\
\hline Média & 16,6 & 5,3 & 4,4 & 87,2 & 4,5 & 2,7 & 0,05 \\
\hline CV \% & 3,3 & 14,5 & 5,4 & 6,4 & 33,1 & 17,2 & 23,8 \\
\hline
\end{tabular}

Médias seguidas por asterisco na coluna diferem da testemunha (silagem in natura) pelo teste de Dunnett $(\mathrm{P}<0,05)$.

Fonte: Elaboração dos autores.

Não houve diferença $(\mathrm{P}>0,05)$ nos valores de $\mathrm{N}-\mathrm{NH}_{3} / \mathrm{NT}$ entre as silagens do CDS aditivadas em relação à silagem do CDS in natura (Tabela 2), sendo observado valor médio de 5,3\% na MS. Os teores de $\mathrm{N}-\mathrm{NH}_{3} / \mathrm{NT}$ encontrados nas silagens não ultrapassaram $10 \%$ e foram próximos aos observados para materiais tradicionais como o milho, sorgo Sudão, sorgo forrageiro e girassol (SANTOS et al., 2010; OLIVEIRA et al., 2010).

Os valores de $\mathrm{pH}$ (Tabela 2) da silagem do
CDS in natura $(\mathrm{pH}=4,1)$ diferiu apenas quando comparada com a silagem do CDS aditivada com farelo de soja $(\mathrm{pH}=4,9)$ e este fato pode ter sido provocado pelo poder tamponante do farelo de soja. Os valores ideais de $\mathrm{pH}$ para promover eficiente conservação da massa ensilada devem estar entre 3,6 e 4,2 (McDONALD; HENDERSON; HERON, 1991). As silagens com CDS in natura $(4,1)$, CDS + torta de licuri $(3,7)$ e CDS + pó da batedeira $(4,2)$ encontraram-se nessa faixa de variação. As silagens dos demais tratamentos apresentaram valores acima 
de 4,2, o que, segundo Tomich et al., (2003) pode não ser suficiente para inibir totalmente o crescimento dos clostrídios.

Quanto aos valores de recuperação de matéria seca (RMS) (Tabela 2), não houve diferença entre as silagens do CDS in natura e com aditivos. Os teores de ácido lático e acético não diferiram $(\mathrm{P}>0,05)$ nas silagens do CDS aditivadas em relação ao material in natura (Tabela 2). As médias dos teores de ácido lático e ácido acético foram de 4,5 e 2,7\% na MS. Kung Júnior (2001) sugeriu teores de 6 a 10\% de ácido lático na MS como ideais para silagens de capins tropicais e estes teores só foram observados nas silagens do CDS aditivadas com farelo de soja e torta de algodão. Santos et al. (2008) e Zanine et al. (2010) trabalhando com silagem de capimelefante, encontraram valores de 4,1 e 4,23\% na MS, respectivamente. Rodrigues et al. (2004) em ensaios com silagens de milho, encontraram valores médios de 2,7\% de ácido lático na MS. Silagens bem conservadas devem apresentar concentrações inferiores a 2,5\% de ácido acético na MS (TOMICH et al., 2003), valores que foram alcançados pela silagem do CDS in natura, aditivada com farelo de soja ou pó da batedeira.

Houve diferença $(\mathrm{P}<0,05)$ nos valores de ácido butírico (Tabela 2) apenas para silagem do CDS aditivada com torta de dendê $(0,07 \%$ na MS) em relação ao material in natura $(0,03 \%$ na MS). O teor de ácido butírico é considerado um dos principais indicadores negativos no processo fermentativo. Segundo Tomich et al. (2003), teores abaixo de $0,1 \%$ correspondem a silagens de excelente qualidade e estes valores foram alcançados em todas as silagens estudadas.
Com exceção da torta de licuri e pó da batedeira (6,4 e 5,9\% de PB na MS, respectivamente), todos os demais aditivos promoveram aumentos significativos $(\mathrm{P}<0,05)$ no teor de $\mathrm{PB}$ da silagem, em relação a silagem com CDS in natura. A ausência de incremento no valor proteico das silagens aditivadas com torta de licuri e pó da batedeira foram causados pelo menor teor de PB destes aditivos em relação ao CDS in natura $(9,5 \%$ de PB na MS). Os valores de PB encontrados para o CDS estão de acordo com o estudo realizado por Faria et al. (2008a) que avaliaram o CDS amonizado, e encontraram valores de PB de 11 e 14\% em CDS in natura e amonizado, respectivamente. Em outro ensaio, Faria et al. (2008b) ao avaliarem o CDS submetido a auto fermentação encontraram teores próximos a $9 \%$ de PB no CDS in natura.

Para os teores de PIDN, os aditivos torta de algodão, torta de dendê e torta de licuri proporcionaram aumento $(\mathrm{P}<0,05)$ na maior proporção de nitrogênio associado à parede celular, enquanto a adição do farelo de trigo resultou na redução $(\mathrm{P}<0,05)$ deste componente protéico.

Houve diferença $(\mathrm{P}<0,05)$ para PIDA nas silagens aditivadas com farelo de soja, torta de algodão, farelo de trigo, torta de dendê e torta de licuri em relação a silagem do CDS in natura (Tabela 3). Os aditivos, farelo de soja e farelo de trigo, proporcionaram redução $(\mathrm{P}<0,05)$ nesta fração protéica da silagem do $\mathrm{CDS}$, enquanto que os aditivos, torta de algodão, torta de dendê e torta de licuri proporcionaram aumento $(\mathrm{P}<0,05)$ na proteína associada a lignina, podendo representar limitações digestivas. 
Tabela 3. Teores de proteína bruta (PB), proteína insolúvel em detergente neutro (PIDN), proteína insolúvel em detergente ácido (PIDA), extrato etéreo (EE), cinzas e nutrientes digestíveis totais (NDT) da silagem do CDS in natura e em função de diferentes aditivos.

\begin{tabular}{lcccccc}
\hline Tratamentos & PB $(\% \mathrm{MS})$ & $\begin{array}{c}\text { PIDN } \\
(\% \mathrm{MS})\end{array}$ & $\begin{array}{c}\text { PIDA } \\
(\% \mathrm{MS})\end{array}$ & EE $(\% \mathrm{MS})$ & $\begin{array}{c}\text { Cinzas } \\
(\% \mathrm{MS})\end{array}$ & $\begin{array}{c}\text { NDT } \\
(\% \mathrm{MS})\end{array}$ \\
\hline CDS in natura & 9,5 & 3,2 & 1,1 & 4,7 & 13,8 & 61,1 \\
CDS + Farelo de soja & $27,2^{*}$ & 3,6 & $0,7^{*}$ & $3,4^{*}$ & 12,7 & 62,5 \\
CDS + uréia & $21,5^{*}$ & 3,1 & 1,1 & 4,6 & 14,9 & $52,7^{*}$ \\
CDS + Torta de algodão & $18,0^{*}$ & $5,5^{*}$ & $1,4^{*}$ & $6,8^{*}$ & 12,6 & $55,4^{*}$ \\
CDS + Farelo de trigo & $14,6^{*}$ & $2,6^{*}$ & $0,8^{*}$ & $3,4^{*}$ & $10,0^{*}$ & 61,7 \\
CDS + Torta de dendê & $11,1^{*}$ & $4,0^{*}$ & $2,1^{*}$ & $7,2^{*}$ & $9,2^{*}$ & $54,9^{*}$ \\
CDS + Pó da batedeira & 9,2 & 3,1 & 1,3 & $3,5^{*}$ & 15,4 & $52,4^{*}$ \\
CDS + Torta de licuri & 9,6 & $4,1^{*}$ & $1,8^{*}$ & $5,6^{*}$ & 11,7 & 62,1 \\
\hline Média & 15,0 & 3,6 & 1,3 & 4,8 & 12,6 & 57,5 \\
\hline CV\% & 3,3 & 4,5 & 8,7 & 5,4 & 9,3 & 2,5 \\
\hline
\end{tabular}

Médias seguidas por asterisco na coluna diferem da testemunha (silagem in natura) pelo teste de Dunnett $(\mathrm{P}<0,05)$.

Fonte: Elaboração dos autores.

Houve diferença $(\mathrm{P}<0,05)$ na concentração de EE entre as silagens aditivadas em relação à silagem do CDS in natura, exceto para a silagem aditivada com uréia (Tabela 3). Os aditivos, torta de algodão (6,8\% na MS), torta de dendê ( $7,2 \%$ na MS) e torta de licuri (5,6\% na MS) proporcionaram aumento na concentração de EE em relação à silagem do CDS in natura, a qual apresentou valores de EE $(4,7 \%$ de $\mathrm{EE}$ ) acima dos observados em forragens tropicais. Faria et al. (2008a) encontraram teores de EE de 1,67 no CDS in natura. Já Harrinson (1984), relatou valor de 3,1\% no CDS in natura em ensaio com bagaço do sisal fresco.

Houve diferença $(\mathrm{P}<0,05)$ nos teores de cinzas (Tabela 3) com relação ao material in natura apenas nas silagens com farelo de trigo e torta de dendê (10,0 e 9,2\% na MS, respectivamente). O valor de cinzas no CDS in natura, foi de $13,8 \%$ na MS, que está próximo ao encontrado por Gebremariam e Machin (2008), de 14,8\% na MS do material in natura. O valor de cinzas na silagem com pó da batedeira (15,4\% na MS) pode ser resultado da forma de obtenção deste coproduto, oriundo da varredura de galpões.

Houve redução $(\mathrm{P}<0,05)$ nos valores estimados de NDT nas silagens aditivadas com uréia $(52,7 \%)$, torta de algodão $(55,4 \%)$, torta de dendê $(54,9 \%)$ e pó da batedeira $(52,4 \%)$ em relação à silagem do CDS in natura (Tabela 3). A silagem in natura apresentou $61,1 \%$ de NDT, valor próximo às médias 64,04, 58,29\% reportadas nas Tabelas Brasileiras de Composição de Alimentos para Ruminantes (VALADARES FILHO et al., 2006) em silagens de milho e sorgo, respectivamente.

Os teores de FDN aumentaram $(\mathrm{P}<0,05)$ entre as silagens do CDS aditivadas com torta de algodão (60,1\% na MS) e torta de dendê $(66,2 \%$ na MS) em relação à silagem do CDS in natura (Tabela 4). A silagem do CDS in natura apresentou $42,9 \%$ de FDN na MS, valor próximo a 39,0 e 41,8\%, observados no CDS avaliados por Faria et al. (2008b) e Faria et al. (2008a), respectivamente. A concentração de FDA nas silagens aditivadas com farelo de soja e farelo de trigo foi reduzida $(\mathrm{P}<0,05)$ em relação à silagem do CDS in natura, enquanto as silagens aditivadas com torta de algodão, torta de dendê e pó da batedeira apresentaram teor de FDA superiores à silagem do CDS in natura, provavelmente decorrentes dos elevados teores de FDA nesses aditivos (Tabela 4). Não houve diferença $(\mathrm{P}>0,05)$ na concentração de lignina 
entre as silagens do CDS aditivadas em relação à silagem do CDS in natura, cujo valor médio entre as silagens foi de $12,3 \%$ de lignina na MS (Tabela 4). Este valor foi maior quando comparado à silagem de sorgo, 7,98\% (CABRAL et al., 2003), silagem de milho, 11,37\% (RODRIGUES et al., 2004) e capim-Elefante, $8,40 \%$ (PINHO et al., 2008), porém menor do que os valores observados em coprodutos regionais do semiárido, como o bagaço de caju, 22,5\% (FERREIRA et al., 2004) e coproduto de vitivinícola, 22,87\% (TOSTO et al., 2008).

Quanto aos teores de CNF (Tabela 4), houve redução em relação à silagem do CDS in natura se comparada àquelas aditivadas com farelo de soja, torta de algodão e torta de dendê. Observouse redução nos seus teores de CHOT em relação à silagem do CDS in natura nas silagens aditivadas com torta de algodão, uréia e farelo de soja, os quais resultaram em 64,3, 57,9 e 56,7\% de CHOT na MS, respectivamente. Este comportamento pode ser explicado pelo incremento no teor de proteínas destes aditivos.

Avaliando-se as silagens segundo critérios sugeridos por Tomich et al. (2003), as silagens do CDS in natura, e aditivadas com farelo de trigo, pó da batedeira e torta de licuri, foram consideradas "excelente", enquanto as silagens aditivadas com farelo de soja, uréia, torta de dendê e torta de algodão foram consideradas como de "boa" qualidade.

Tabela 4. Teores de fibra em detergente neutro (FDN), fibra em detergente ácido (FDA), lignina (LIG), carboidratos não fibrosos (CNF) e carboidratos totais (CHOT) da silagem do CDS in natura e em função de diferentes aditivos.

\begin{tabular}{lccccc}
\hline Tratamentos & FDN $(\% \mathrm{MS})$ & FDA $(\% \mathrm{MS})$ & $\begin{array}{c}\text { Lignina } \\
(\% \mathrm{MS})\end{array}$ & CNF (\%MS) & $\begin{array}{c}\text { CHOT } \\
(\% \mathrm{MS})\end{array}$ \\
\hline CDS in natura & 42,9 & 31,7 & 12,6 & 30,3 & 71,2 \\
CDS + Farelo de soja & 47,0 & $26,5^{*}$ & 9,6 & $13,4^{*}$ & $56,7^{*}$ \\
CDS + uréia & 49,2 & 34,2 & 13,3 & 17,9 & $57,9^{*}$ \\
CDS + Torta de algodão & $60,1^{*}$ & $38,0^{*}$ & 12,0 & $16,4^{*}$ & $64,3^{*}$ \\
CDS + Farelo de trigo & 50,4 & $26,5^{*}$ & 9,7 & 24,4 & 72,0 \\
CDS + Torta de dendê & $66,2^{*}$ & $45,1^{*}$ & 15,6 & $11,1^{*}$ & 71,2 \\
CDS + Pó da batedeira & 51,8 & $37,7^{*}$ & 13,3 & 25,9 & 71,2 \\
CDS + Torta de licuri & 42,3 & 32,3 & 13,9 & 34,9 & 72,0 \\
\hline Média & 52,1 & 33,1 & 12,3 & 22,3 & 66,9 \\
\hline CV\% & 7,1 & 3,9 & 13,9 & 15,1 & 2,6 \\
\hline
\end{tabular}

Médias seguidas por asterisco na coluna diferem da testemunha (silagem in natura) pelo teste de Dunnett $(\mathrm{P}<0,05)$.

Fonte: Elaboração dos autores

Os critérios utilizados por esses autores incluíram os teores de $\mathrm{pH}$ associado aos teores de MS, N-NH$/$ NT, ácido acético e ácido butírico. O que mais influenciou na qualificação das silagens foram os teores de MS, que influiu diretamente nos teores de pH e nos valores de ácido acético. O maior aporte de proteína alcançado com a adição dos aditivos como uréia, farelo de soja e torta de algodão, associados aos baixos teores de MS do CDS, pode ter criado condições menos favoráveis para as fermentações desejáveis e consequentemente, influenciaram negativamente na qualidade das silagens.

\section{Conclusões}

A maioria dos aditivos (farelo de soja, torta de algodão, farelo de trigo, torta de dendê) utilizados na ensilagem do coproduto do desfibramento do sisal aumenta o teor de MS e PB das silagens. 
O pó da batedeira (material oriundo da varredura dos galpões de armazenamento e processamento da fibra) e a torta de licuri melhoram as concentrações de MS e a uréia melhora a concentração de PB.

Dentre os aditivos utilizados para ensilagem do coproduto do desfibramento do sisal, o farelo de trigo é o que mais proporciona benefícios, melhorando as concentrações de MS, PB, PIDN, PIDA, cinzas, NDT e FDA;

Todas as silagens contendo aditivos são de boa ou de excelente qualidade.

\section{Referências}

BOLSEN, K. K.; LIN, C.; BRENT, B. E.; FEYERHERM, A. M.; URBAN, J. E.; AIMUTIS, W. R. Effect of silage additives on the microbial succession and fermentation process of alfalfa and corn silages. Journal of Dairy Science, Champaign, v. 75, n. 11, p. 3066-3083, 1992.

CABRAL, L. S.; VALADARES FILHO, S. C.; DETMANN, E.; ZERVOUDAKIS, J. T.; PEREIRA, O. G.; VELOSO, R. G. Composição químicobromatológica, produção de gás, digestibilidade in vitro da matéria seca e NDT estimado da silagem de sorgo com diferentes proporções de panículas. Revista Brasileira de Zootecnia, Viçosa, MG, v. 32, n. 5, p. 1250-1258, 2003.

COMPANHIA NACIONAL DE ABASTECIMENTO CONAB. Volume exportado e geração de divisas do sisal em 2008. Disponível em: <www.conab.gov.br>. Acesso em: 20 maio 2010.

FARIA, M. M. de S.; JAEGER, S. M. P. L.; OLIVEIRA, G. J. C. de; OLIVEIRA, R. L.; LEDO, C. A. da S.; SILVA, A. M. da; LOPES, N. C. M.; SANTANA, F. S. de. Composição bromatológica do co-produto do desfibramento do sisal submetido à auto-fermentação. Magistra, Cruz das Almas, v. 20, n. 1, p. 30-35, 2008 b.

FARIA, M. M. de S.; JAEGER, S. M. P. L.; OLIVEIRA, G. J. C.; OLIVEIRA, R. L.; LEDO, C. A. S.; SANTANA, F. S. Composição bromatológica do coproduto do desfibramento do sisal tratado com ureia. Revista Brasileira de Zootecnia, Viçosa, MG, v. 37, n. 3, p. 377 382, 2008a.

FERREIRA, A. C. H.; NEIVA, J. N. M.; RODRIGUEZ, N. M.; LÔBO, R. N. B.; VASCONCELOS, V. R. Valor nutritivo das silagens de capim-elefante com diferentes níveis de subprodutos da indústria do suco de caju. Revista Brasileira de Zootecnia, Viçosa, MG, v. 33, n. 6, p. 1380-1385, 2004.
GEBREMARIAM, D. Y.; MACHIN, D. H. Evaluation of sun dried sisal pulp (Agave sisalana Perrine) as feed for sheep in Eritrea. Livestock Research Rural Development, Cali, v. 20, n. 11, p. 183, 2008.

HARRINSON, D. G. Subprodutos del sisal como alimentos para los ruminates. Revue Mundiale de Zootechnie, Roma, v. 49, n. 1, p. 25-31, 1984.

KUNG JÚNIOR, L. Aditivos microbianos e químicos para silagem: efeitos na fermentação e resposta animal. In: WORKSHOP SOBRE MILHO PARA SILAGEM, 2., 2001, Piracicaba. Anais... Piracicaba: Fundação de Estudos Agrários Luiz de Queiroz, 2001. p. 53-74.

McDONALD, P.; HENDERSON, A. R.; HERON, S. J. E. The biochemistry of silage. 2. ed. Marlow: Chalcombe Pub, 1991. 340p.

NATIONAL RESEARCH COUNCIL - NRC. Nutrient requirements of dairy cattle. 7. ed. rev. Washington D.C.: National Academy Press, 2001. 360 p.

OLIVEIRA, L. B.; PIRES, A. J. V.; CARVALHO, G. G. P.; RIBEIRO, L. S. O.; ALMEIDA, V. V.; PEIXOTO, C. A. M. Perdas e valor nutritivo de silagens de milho, sorgosudão, sorgo forrageiro e girassol. Revista Brasileira de Zootecnia, Viçosa, MG, v. 39, n. 1, p. 61-67, 2010.

PINHO, B.; PIRES, A. J. V.; RIBEIRO, L. S. O.; CARVALHO, G. G. P. Ensilagem de capim-elefante com farelo de mandioca. Revista Brasileira de Saúde e Produção Animal, Salvador, v. 9, n. 4, p. 641-651, 2008.

RIBEIRO, C. G. M.; GONÇALVES, L.C.; RODRIGUES, J. A. S.; RODRIGUEZ, N. M.; BORGES, I.; BORGES, A. L. C. C.; SALIBA, E. O. S.; CASTRO, G. H. F.; RIBEIRO JUNIOR, G. O. Padrão de fermentação da silagem de cinco genótipos de sorgo. Arquivos Brasileiro de Medicina Veterinária e Zootecnia, Belo Horizonte, v. 59, n. 6, p. 1531-1537, 2007.

RODRIGUES, P. H. M.; RUZANTE, J. M.; SENATORE, A. L.; LIMA, F. R.; MELOTTI, L.; MEYER, P. M. Avaliação do uso de inoculantes microbianos sobre a qualidade fermentativa e nutricional da silagem de milho. Revista Brasileira de Zootecnia, Viçosa, MG, v. 33, n. 3, p. 538-545, 2004.

SANTOS, E. M.; ZANINE, A. M.; DANTAS, P. A. S.; DÓREA, J. R. R.; SILVA, T. C.; PEREIRA, O. G.; LANA, R. P.; COSTA, R. G. Composição bromatológica, perdas e perfil fermentativo de silagens de capim-elefante com níveis de inclusão de jaca. Revista Brasileira de Saúde e Produção Animal, Salvador, v. 9, n. 1, p. 64-73, 2008.

SANTOS, R. D.; PEREIRA, L. G. R.; NEVES, A. L. A.; ARAÚJO, G. G. L.; VOLTOLINI, T. V.; BRANDÃO, L. G. N.; ARAGÃO, A. S. L.; DÓREA, J. 
R. R. Características de fermentação da silagem de seis variedades de milho indicadas para a região semiárida Brasileira. Arquivo Brasileiro de Medicina Veterinária e Zootecnia, Belo Horizonte, v. 62, n. 6, p. 1423-1429, 2010.

SILVA, D. J.; QUEIROZ, A. C. Análise de alimentos: métodos químicos e biológicos. Viçosa, MG: Editora UFV, 2002. $235 \mathrm{p}$.

SILVA, O. R. R. F.; CARVALHO, O. S.; MOREIRA, J. A. N.; BANDEIRA, D. A.; COSTA, L. B.; ALVES, I. Peneira rotativa CNPA, uma alternativa para o aproveitamento da mucilagem na alimentação animal. Campina Grande: EMBRAPA-CNPA, 1998. 15 p. (Boletim de Pesquisa, 36).

SNIFFEN, C. J.; O’CONNOR, J. D.; VAN SOEST, P. J.; FOX, D. G.; RUSSEL, J. B. A net carbohydrate and protein system for evaluating cattle diets: II. Carbohydrate and protein availability. Journal of Animal Science, Champaign, v. 70, n. 11, p. 3562-3577, 1992.

STATISTICAL ANALYSES SYSTEM - SAS. SAS user's guide. Cary: SAS Institute In, 1999. v. 8, 295 p.
TOMICH, T. R.; PEREIRA, L. G. R.; GONÇALVES, L. C.; TOMICH, R. G. P.; BORGES, I. Características químicas para avaliação do processo fermentativo de silagens: uma proposta para qualificação da fermentação. Corumbá: Embrapa Pantanal, 2003. 20 p.

TOSTO, M. S. L.; ARAÚJO, G. G. L.; OLIVEIRA, R. L.; JAEGER, S. M. P. L.; MENEZES, D. R.; DANTAS, F. R. Utilização de uréia no resíduo desidratado de vitivinícola associado à palma forrageira na alimentação de caprinos: consumo e digestibilidade de nutrientes. Revista Brasileira de Zootecnia, Viçosa, MG, v. 37, n. 10, p. 1890-1896, 2008.

VALADARES FILHO, S. C.; MACHADO, P. A. S.; CHIZZOTTI, M. L.; AMARAL, H. F.; MAGALHÃES, K. A.; ROCHA JUNIOR, V. R.; CAPELLE, E. R. Tabelas brasileiras de composição de alimentos para bovinos. Viçosa, MG: UFV, 2006. 329 p.

ZANINE, A. M.; SANTOS, E. M.; DÓREA, J. R. R.; DANTAS, P. A. S.; SILVA, T. C.; PEREIRA, O. G. Evaluation of elephant grass silage with the addition of cassava scrapings. Revista Brasileira de Zootecnia, Viçosa, MG, v. 39, n. 12, p. 2611-2616, 2010. 
